\title{
Variation of the cholesterol content in breast milk during 10 days collection at early stages of lactation
}

\author{
Anna M. Kamelska', Renata Pietrzak-Fiećko ${ }^{2}$ and Krzysztof Bryl ${ }^{1}$ \\ ${ }^{1}$ Chair of Physics and Biophysics and ${ }^{2}$ Chair of Commodities and Food Analysis, Faculty of Food Sciences, University of Warmia and Mazury in \\ Olsztyn, Olsztyn, Poland
}

\begin{abstract}
More and more research is done concerning nutritional programming. Human milk nutrients which are consumed by infants can influence their health in later life. High level of cholesterol in human milk paradoxically lowers the cholesterol concentration in blood in adults. During the course of human lactation the cholesterol concentration decreases from $31 \mathrm{mg} / 100 \mathrm{~cm}^{3}$ (colostrum) to $16 \mathrm{mg} / 100 \mathrm{~cm}^{3}$ (mature milk). According to Scopesi et al., 2002, Clin Nutr 21: 379-384, cholesterol concentration in mature milk ranged from 6.5 to $18.4 \mathrm{mg} / 100$ $\mathrm{cm}^{3}$. The aim of the study was to assess the variations in breast milk cholesterol content during 10 day collection at early lactation. 48 samples of human milk were analyzed. Mean age of women was 31 years. Women were collecting samples during 10 days of an early lactation stage (1-3 months after delivery). An Attenuated Total Reflectance Fourier Transformed Infrared (FTIRATR) method for easy and rapid determination of cholesterol in human milk was elaborated. Cholesterol content assessed by the FTIR method ranged from 3.36 to $12.98 \mathrm{mg} / 100 \mathrm{~cm}^{3}$. Results indicate that milk cholesterol concentration during 10 consecutive days of early lactation is highly variable. Cholesterol content depends on an individual. Therefore it is suggested that not only the period of lactation but also mother's diet, age, season and place of residence are important factors determining cholesterol content.
\end{abstract}

Key words: cholesterol variations, human milk, FTIR-ATR spectroscopy

Received: 11 August, 2011; revised: 29 March, 2012; accepted: 04 April, 2012; available on-line: 27 April, 2012

\section{INTRODUCTION}

The human milk is considered as being the gold standard of infant nutrition (Kowalewska-Kantecka, 2007). Its composition depends mainly on a growing infant's needs and also on mother's metabolism. Breast-feeding positively influences the child's proper development by stimulating the immune system, digestive system and others. The components contained in milk such as growth factors, cytokines, immunoglobulins, lactoferrin, immunocompetent cells have a beneficial effect on the infant's body (Koletzko et al., 2005). The metabolic events at a critical pre- and postnatal time largely affect health in later life (Koletzko, 2005; Koletzko et al., 2005). This is called nutritional programming.

Currently, a lot of research has been done on cholesterol, which is perceived to be an important factor in cardiovascular diseases (Castelli et al.., 1986; Castelli et al.,
1992). On the other hand, cholesterol is also important in proper development of nervous system, hormone and vitamin synthesis in a growing infant (Adams \& Hollis, 2002; Harvey et al., 2005; Dietschy \& Turley, 2004).

The influence of infant plasma cholesterol levels on atherosclerosis development is still unknown (Agostini \& Riva, 1998). According to studies by Reiser and Sidelman (Reiser \& Sidelman, 1972) an inverse correlation between maternal milk cholesterol content and cholesterol in the blood plasma in the adult rat has been demonstrated. These studies became the starting point for attempts to determine the effect of the concentration of cholesterol delivered through milk on its metabolism in later life. Owen et al. (2008) showed that a high level of cholesterol in human milk paradoxically lowers the cholesterol concentration in blood in later life. Feeding infants breast milk containing high cholesterol affects normal metabolism of this compound and prevents the occurrence of hypercholesterolemia in later life.

A proper methodology to measure cholesterol concentration has not been developed yet. The authors use different methods and obtain divergent results. It is therefore necessary to calibrate methods used to assess the content of cholesterol. Cholesterol concentration in human milk is lower than in cow's milk (10.20-19.68 mg/ dl) (Talpur et al., 2006) and higher than in infant formulas. Cholesterol concentration in infant formulas (0.93$5.45 \mathrm{mg} / 100 \mathrm{~cm}^{3}$ ) (Kamelska et al., 2011) is relatively low as compared to breast milk. Mean cholesterol level in breast milk assessed by Hamosh (1998) was $15 \mathrm{mg} /$ dL. During the course of human lactation the cholesterol concentration decreases from $31 \mathrm{mg} / 100 \mathrm{~cm}^{3}$ (colostrum) to $16 \mathrm{mg} / 100 \mathrm{~cm}^{3}$ (mature milk) (Emmett \& Rogers, 1997). Other authors assessed cholesterol concentration in mature milk ranging between $10-18 \mathrm{mg} / 100 \mathrm{~cm}^{3}$ (Kalio et al., 1989). According to Scopesi et al. (2002) cholesterol content in breast milk was in the range of $6.5-18.4 \mathrm{mg} / 100 \mathrm{~cm}^{3}$. Cholesterol concentration may increase during lactation. Breast milk also contains sterols and other metabolites of cholesterol biosynthesis (Kalio et al., 1989).

Cholesterol concentration in dairy products can be determined by various methods such as: colorimetry (Bachman et al., 1976), gas chromatography (Alonso et al., 1995; Fletouris et al., 1998), Fourier Transformed Infrared spectroscopy FTIR (Paradkar \& Irudayaraj, 2002) and Attenuated Total Reflectance Fourier Transformed

e-mail: malwak1@gmail.com

Abbreviations: AUC, area under curve; CV, coefficient of variation; FTIR-ATR, attenuated total reflectance fourier transformed infrared spectroscopy; GC, gas chromatography; S.D., standard deviation. 
Infrared spectroscopy FTIR-ATR (Arsov \& Quaroni, 2008). But none of them is suitable for human milk cholesterol content determination. Finding a cheap and rapid method for human milk is essential. Infrared spectroscopy FTIR-ATR has been previously adopted by us in order to determine cholesterol content in infant formulas (Kamelska et al., 2010).

The aim of the study was to assess the variations in breast milk cholesterol content during a 10 day collection at early lactation (1-3 months after delivery) using the FTIR-ATR method.

\section{MATERIALS AND METHODS}

Materials. Human milk samples from lactating mothers with no parental history of hypercholesterolemia and/ or hypertriglyceridemia were colected from June 2007 to August 2008. All women were living in the Warmia and Mazury region of Poland. All mothers were non smokers. 48 samples from 1 to 3 months postpartum were collected. This period was assigned by the authors as an "early stage of lactation". Samples have been collected immediately after infant breastfeeding once per day at the same time. The milk was taken from the breast not used for child feeding. All milk samples were frozen in plastic containers and stored immediately at $-20^{\circ} \mathrm{C}$ until analysis. The milk remaining after cholesterol analysis was used for determination of other components.

Women at the age of 24-34 years (mean \pm S.D. = $31 \pm 4.5$ years) were collecting samples during 10 consecutive days. Body mass index (BMI) was calculated as weight (in $\mathrm{kg}$ ) $\div$ height $^{2}$ (in $\mathrm{m}^{2}$ ). Table 1 shows characteristics of the coded population studied.

This research was approved by the Ethics Committee of the Medical University of Bialystok No. R-I$003 / 22 / 2000$ and performed with the mothers who agreed to take part in this study.

Table 1. Characteristics of the population studied

\begin{tabular}{lcc}
\hline Characteristic Factor & Specification & $\begin{array}{c}\text { Number of } \\
\text { samples }\end{array}$ \\
\hline Place of living & Village & 0 \\
Smoking & City & 49 \\
Education & Nos & 0 \\
& Elementary & 49 \\
Lactation (month) & Secondary & 0 \\
& Higher & 10 \\
Mothers' age & $1^{\text {st }}$ & 29 \\
(years) & $2^{\text {nd }}$ & 0 \\
& $3^{\text {rd }}-4^{\text {th }}$ & 20 \\
Mean mothers' height $(\mathrm{cm})$ & 24 & 10 \\
Mean mothers' weight $(\mathrm{kg})$ & 167.8 & 10 \\
Mean BMI $( \pm$ S.D.) & 63.4 & 29 \\
BMI MIN & $22.52 \pm 3.22$ & \\
BMI MAX & 19.47 & \\
\hline
\end{tabular}

Reagents. Pure cholesterol standard was obtained from Sigma Aldrich Company. Hexane was obtained from Merck KGaA. Ethanol (96\%) was purchased from Eurochem BGD Tarnow Company (Poland). Chloroform was supplied by POCH.

Isolation of cholesterol from human milk. The method of cholesterol determination in dairy products e.g. yogurt, butter was used by Paradkar and Irudayaray (2002). The authors of this study adopted this method for human milk. Stock solution was prepared by dissolving pure cholesterol powder in chloroform (2 g per 100 $\left.\mathrm{cm}^{3}\right)$. The appropriate dilutions of cholesterol concentration from 2 to $14 \mathrm{mg} / \mathrm{cm}^{3}$ were prepared from the stock solution. The cholesterol content range was consistent with the cholesterol content of the samples analyzed.

Human milk samples, $2 \mathrm{~cm}^{3}$, were placed in a test tube. $9 \mathrm{~cm}^{3}$ of ethanol and $1 \mathrm{~cm}^{3}$ of potassium hydroxide solution $\left(50 \mathrm{~g}\right.$ per $100 \mathrm{~cm}^{3}$ ) were added and all was vortex mixed for $20 \mathrm{~s}$. The capped test tube was then placed in a water bath at $60^{\circ} \mathrm{C}$, saponified and stirred continuously at 200 r.p.m for 1 h. After cooling to room temperature, $5 \mathrm{~cm}^{3}$ of deionized water and $10 \mathrm{~cm}^{3}$ of hexane were added and vortex mixed for approximately 2 min. The sample was then centrifuged for $3 \mathrm{~min}$ at 2000 r.p.m. and the upper hexane layer was transferred with a pipette into a clean test tube. Another $10 \mathrm{~cm}^{3}$ portion of hexane was added to the water phase. The extraction and the centrifugation steps were repeated. The combined hexane extract was then used for cholesterol determination. The hexane extract was evaporated to dryness and the sample was re-dissolved in $5 \mathrm{~cm}^{3}$ of chloroform and used for FTIR analysis (Paradkar \& Irudayaraj, 2002).

Analysis of human milk samples by FTIR-ATR method. A 7000e Digilab spectrometer equipped with a deuterated triglycine sulphate detector was used for FTIR analysis. The sampling station was equipped with an ATR accessory, comprising transfer optics within the chamber through which infrared radiation is directed to

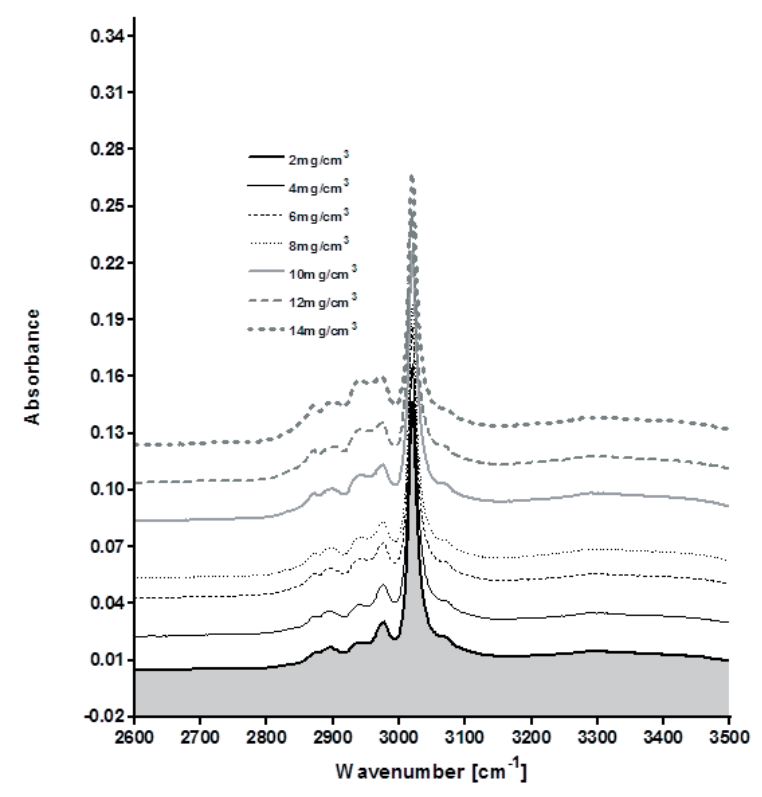

Figure 1. FTIR-ATR spectra of cholesterol standards at different concentration ranging from $2 \mathrm{mg} / \mathrm{cm}^{3}$ to $14 \mathrm{mg} / \mathrm{cm}^{3}$ at intervals of $2 \mathrm{mg} / \mathrm{cm}^{3}$.

Spectra are normalized to the same value of absorbance at 4000 $\mathrm{cm}^{-1}$. For the sake of clarity, spectra are parallel shifted. 


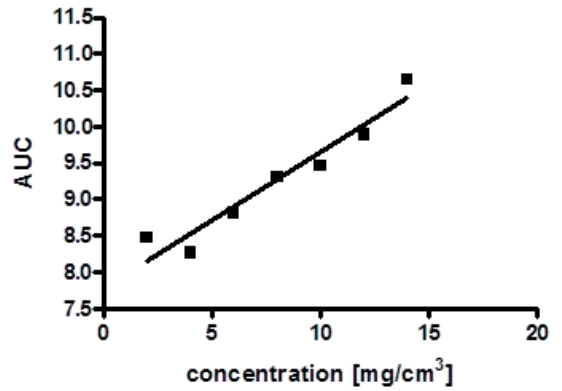

Figure 2. FTIR-ATR calibration plot for cholesterol using the spectral region between 2800 and $3200 \mathrm{~cm}^{-1}$ : AUC (area under curve).

Coefficient of determination $r^{2}=0.9303$ (adopted from Kamelska et al., 2010).

a detachable ATR zinc selenide crystal (Pike Technologies) mounted in a shallow trough for sample containment.

The spectrum of a clean ATR crystal was used as the background and cholesterol extract from human milk samples was dissolved in chloroform and used for FTIR analysis. FTIR-ATR spectra were obtained during 16 scans from $400-4000 \mathrm{~cm}^{-1}$. The ATR crystal was carefully cleaned with pure chloroform after each measurement.

The data were analyzed and prepared in the GraphPad Prism program.

Statistical analysis. The human milk samples were homogenously selected so as to find differences in human milk cholesterol fluctuations depending only on the stage of lactation. Data for the human milk are presented as mean and standard deviation. One-way ANOVA was applied to find differences between cholesterol concentration in groups from different months of lactation.

The correlation between other factors (weight and BMI) and cholesterol concentration in human milk was shown as Pearson's correlation coefficient. All statistical analyses were done using STATISTICA 10.0.

\section{RESULTS}

\section{Calibration of the method}

Normalized FTIR-ATR spectra of the cholesterol standard at concentrations from 2 to $14 \mathrm{mg} / \mathrm{cm}^{3}$ with the intervals of $2 \mathrm{mg} / \mathrm{cm}^{3}$ in the spectral range from 4000 to $2500 \mathrm{~cm}^{-1}$ are presented in Fig. 1. The absorbance of the prepared cholesterol standards was assessed according to the peak height or the extended area of the

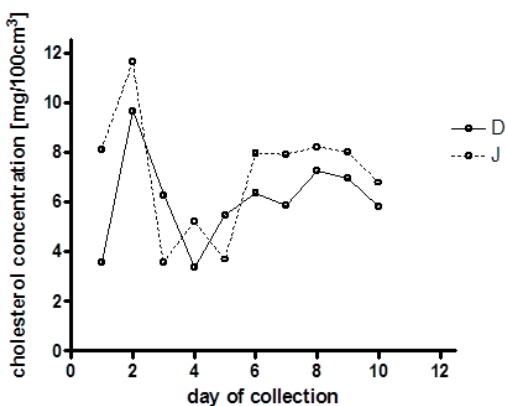

Figure 3. Cholesterol concentration variations during 10 days of collection in the first month of lactation (samples D and J).

spectral region between 2800 and $3000 \mathrm{~cm}^{-1}$. This region is correlated with symmetric and asymmetric vibrations of $\mathrm{CH}_{2}$ and $\mathrm{CH}_{3}$ groups and is diagnostic for cholesterol content determination (Paradkar \& Irudayaraj, 2002). However, these vibrations are characteristic for different compounds identified in oil (Lai, 1995), animal fat, cake and chocolate adulterations (Syahariza, 2005). Therefore, when analyzing one constituent of multivariate mixture one needs to prepare a precise calibration curve. The calibration curve based on cholesterol standards was prepared taking into account the correlation between Area Under Curve (AUC) and concentration (Fig. 2).

In order to perform quantitative analysis of the results it was necessary to validate FTIR-ATR method.

\section{Validation of the method and determination of cholesterol content in human milk samples}

The aim of the study was to assess the variations in breast milk cholesterol content during 10 days of early lactation using an easy, rapid and cheap method for human milk cholesterol content determination. FTIR-ATR can be used in this case, but the method should be validated. Raw milk samples can't be analyzed directly in relation to their various constituents. Thus specific sample preparation was needed.

The Region between $2800 \mathrm{~cm}^{-1}$ and $3200 \mathrm{~cm}^{-1}$ was used for identification of cholesterol bands. This region is responsible for $\mathrm{C}-\mathrm{H}$ stretching vibrations of methyl groups and vibrations of cyclic hydrocarbons, which are characteristic of cholesterol.

Cholesterol content assessed by the FTIR-ATR method ranged from 3.36 to $12.98 \mathrm{mg} / 100 \mathrm{~cm}^{3}$ (Table 2). There were no statistically significant differences between cholesterol concentration in samples from different months of lactation $(p=0.16)$. The minimal and maximal

Table 2. Cholesterol concentration $\left(\mathrm{mg} / 100 \mathrm{~cm}^{3}\right)$ in samples of human milk from different stages of lactation. D, J, W, AG, F - sample code

\begin{tabular}{|c|c|c|c|c|c|c|c|c|c|c|}
\hline \multirow{3}{*}{ Sample code } & \multicolumn{10}{|c|}{ Day of collection } \\
\hline & \multicolumn{10}{|c|}{ Cholesterol concentration $\left(\mathrm{mg} / 100 \mathrm{~cm}^{3}\right)$} \\
\hline & 1 & 2 & 3 & 4 & 5 & 6 & 7 & 8 & 9 & 10 \\
\hline D & 3.57 & 9.66 & 6.27 & 3.36 & 5.45 & 6.35 & 5.86 & 7.24 & 6.96 & 5.78 \\
\hline J & 8.11 & 11.65 & 3.54 & 5.19 & 3.68 & 7.96 & 7.90 & 8.22 & 7.98 & 6.77 \\
\hline W & 11.95 & 4.26 & 5.91 & 6.75 & 7.96 & 4.47 & 4.43 & 12.51 & 12.98 & 5.93 \\
\hline AG & 5.12 & 9.05 & 8.23 & 8.47 & 8.99 & 10.38 & 7.48 & 7.15 & 8.15 & - \\
\hline $\mathrm{F}$ & 8.07 & 10.74 & 5.80 & 7.65 & 6.62 & 6.70 & 8.06 & 8.41 & 8.11 & - \\
\hline
\end{tabular}


Table 3. Mean, minimal, maximal, standard deviation (S.D.) and coefficient of variation (CV) of samples studied.

D, J, W, AG, F - sample code

\begin{tabular}{lllllll}
\hline $\begin{array}{l}\text { Sample } \\
\text { code }\end{array}$ & $\begin{array}{l}\text { Month of } \\
\text { lactation }\end{array}$ & $X$ & MIN & MAX & SD & CV \\
\hline D & 1 & 6.05 & 3.36 & 9.66 & 1.80 & 29.81 \\
J & 1 & 7.10 & 3.54 & 11.65 & 2.43 & 34.30 \\
W & 2 & 7.71 & 4.26 & 12.98 & 3.49 & 45.21 \\
AG & 2 & 8.11 & 5.12 & 10.38 & 1.47 & 18.10 \\
F & 3 & 7.80 & 5.80 & 10.74 & 1.41 & 18.05 \\
\hline
\end{tabular}

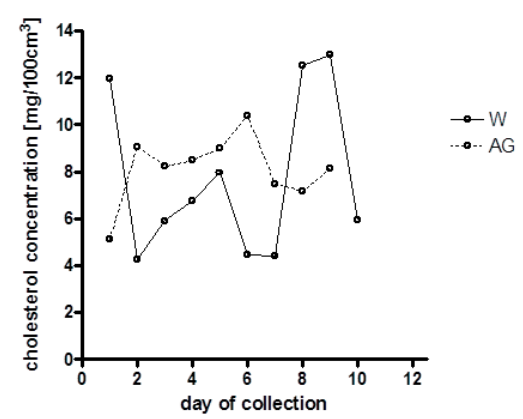

Figure 4. Cholesterol concentration variations in the second month of lactation (samples W and AG).

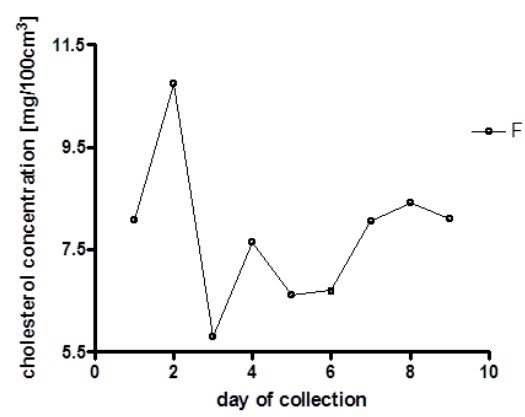

Figure 5. Cholesterol concentration variations during 9 days of collection in the third month of lactation (sample F).

value of cholesterol concentration in the first month of lactation was 3.36 and $11.65 \mathrm{mg} / 100 \mathrm{~cm}^{3}$, respectively. In the second month of lactation these values were 4.26 and $12.98 \mathrm{mg} / 100 \mathrm{~cm}^{3}$ and for the third month of lactation 5.8 and $10.74 \mathrm{mg} / 100 \mathrm{~cm}^{3}$ (Table 3). Cholesterol content variations in samples from the first, second, and third month of lactation are shown in Figs. 3-5.

Empirical data clearly indicate a high negative correlation between mothers' weight and mean cholesterol concentration $(r=-0.8072)$. There was also a high negative correlation between mothers' weight and the minimal value of cholesterol concentration $(r=-0.9907)$. There was a very weak correlation between mothers' weight and the maximal value of cholesterol concentration $(r=-0.1667)$.

\section{DISCUSSION}

There are not many scientific publications about cholesterol content determination in human milk. According to Scopesi (Scopesi et al., 2002) the cholesterol content in human milk is in the range of $6.5-18.4 \mathrm{mg} / 100$ $\mathrm{cm}^{3}$. However these authors did not analyze cholesterol concentration during consecutive days of lactation. According to our findings the cholesterol content assessed by the FTIR-ATR method ranged from 3.36 to 12.98 $\mathrm{mg} / 100 \mathrm{~cm}^{3}$. This range is very similar to that described by Scopesi.

We analyzed cholesterol content variations during 10 days of collection. The mean cholesterol concentration was comparable in the first, second and third month of lactation and did not decrease during 10 consecutive days of collection. Therefore other factors, such as influence of diet, should be analyzed.

According to our findings it is assumed that the FTIR-ATR method is very accurate for cholesterol content determination. It is an easy, powerful, cheap and nondestructive method. Cholesterol content determination in human milk is essential not only for mothers but also for the health of a newborn in his/her adult life.

Preparations of samples for FTIR investigations were less destructive and simpler than those for other methods e.g. chromatography. The latter method requires $0.5 \mathrm{~g}$ of fat from a sample of human milk. It is very difficult to collect a sufficient amount of milk from mothers who are feeding their babies.

The region between $2800 \mathrm{~cm}^{-1}-3200 \mathrm{~cm}^{-1}$ is accurate for cholesterol content determination. However, there is a need to find new diagnostic peaks for cholesterol determination in human milk. Attempts to use absorption maxima at $2400 \mathrm{~cm}^{-1}$ and $2450 \mathrm{~cm}^{-1}$ have been undertaken. This region may correspond to the absorption maximum of pure cholesterol in chloroform (Channa et al., 2008). A very strong absorption band of $\mathrm{CO}_{2}$ is observed in this region so the analysis is very difficult. The great advantage of FTIR spectroscopy is the ability to simultaneously record a registration signal (absorbance) over very broad spectral range.

\section{CONCLUSIONS}

Cholesterol concentrations differ significantly between individual days of collection but do not differ significantly in different months of lactation. There was a negative correlation between mothers' weight and cholesterol concentration in human milk. It can be concluded that not only the stage of lactation, but also individual predispositions and mothers' diet can influence cholesterol concentration in human milk, which should be analyzed in later studies.

FTIR-ATR spectroscopy was successfully used for rapid determination of cholesterol in human milk. The calibration model using area under curve in the 2800$3200 \mathrm{~cm}^{-1}$ frequency band was found to be the most accurate in this study. The method used was rapid and less expensive than the conventional methods. FTIR-ATR spectroscopy results can be obtained in less than 5 min.

\section{REFERENCES}

Adams JS, Hollis B (2002) Vitamin D: Synthesis, Metabolism, and Clinical Measurement. In Disorders of Bone and Mineral Metabolism. Coe FL, Favus MJ, eds, 159. Lippincott Williams and Wilkins. Philadelphia.

Agostini C, Riva E (1998) Dietary fatty acids and cholesterol in the first 2 years of life. Prostaglandins, Leukot Essent Fatty Acids 58: 33-37.

Alonso L, Lozada L, Fontecha J, Juirez M (1995) Determination of cholesterol in milk fat by gas chromatography with direct injection and sample saponification. Chromatographia 41: 23-28.

Arsov Z, Quaroni L (2008) Detection of lipid phase coexistence and lipid interactions in sphingomyelin/cholesterol membranes by ATRFTIR spectroscopy. Biochim Biophys Acta 1778: 880-889. 
Bachman KC, Lin JH, Wilcox CJ, (1976) Sensitive colorimetric determination of cholesterol in dairy products. J Assoc Off Anal Chem 59: 1146-1149.

Castelli WP, Anderson K, Wilson PW, Levy D (1992) Lipids and risk of coronary heart disease: the Framingham Study. Ann Epidemiol 2: 23-28.

Castelli WP, Garrison RJ, Wilson PW, Abbott RD, Kalousdian S, Kannel WB (1986) Incidence of coronary heart disease and lipoproteincholesterol levels: the Framingham Study. JAMA 256: 2835-2838.

Channa NA, Khand FD., Bhanger MI (2008) Analysis of human gallstones by FTIR. Malaysian I Anal Sci 12: 552-560.

Dietschy JM, Turley SD (2004) Cholesterol metabolism in the central nervous system during early development and in the mature animal. J Lipid Res 45: 1375-1397.

Emmett PM, Rogers IS (1997) Properties of human milk and their relationship with maternal nutrition. Early Hum Dev 49 (Suppl): S7S28.

Fletouris DJ, Botsoglou NA, Psomas IE, Mantis AI (1998) Rapid determination of cholesterol in milk and milk products by direct saponification and capillary gas chromatography. J Dairy Sci 81: 28332840.

Hamosh M. (1988) Fat needs for term and preterm infants. In: Nutrition during infancy. Tsang RC, Nichols BL, eds, pp 133-159. Hanley \& Belfus Inc., Philadelphia.

Harvey et al. (2005) Biochemistry. 3rd edn, 235-238. Baltimore: Lippincott.

Kallio MJT, Siimes MA, Perheentupa J, Salmenpera LS, Miettinen TA (1989) Cholesterol and its precursors in human milk during prolonged exclusive breast-feeding. Am J Clin Nutr 50: 782-785.

Kamelska AM, Pietrzak-Fiećko R, Bryl K (2010) Analysis of selected infant formula samples including cholesterol determination by FTIR-ATR method. In: The quality and bealth promoting qualities of food. Wojtatowicz M, Kawa-Rygielska J, eds, pp 87-99. Wroclaw University of Environmental and Life Sciences Publishing House, Wroclaw, Poland.
Kamelska AM, Pietrzak-Fiećko R, Bryl K (2011) Cholesterol content as an infant formulas quality determinant. University of Economics in Poznan Scientific Papers 196: 38-45.

Koletzko B (2005) Developmental origins of adult disease: Barker's or Dörner's hypothesis? Am J Hum Biol 17: 381-382.

Koletzko B, Akerblom H, Dodds PF, Ashwell M (Hrsg.) (2005) Early nutrition and its later consequences: New opportunities. New York, Springer Publishers. Adv Exp Med Biol 569: 1-237.

Kowalewska-Kantecka B (2007) Breastfeeding- the gold standard of infant nutrition. Contemporary Pediatrics. Gastroenterology, Hepathology and Child Nutr 9: 65-68.

Lai YW, Kemsley EK, Wilson RH (1995) Quantitative analysis of potential adulterant of extra virgin olive oil using IR spectroscopy. Food Chem 53: 95-98.

Owen CG, Whincup P H, Kaye SJ, Martin RM, Smith GD, Cook DG, et al. (2008) Does initial breastfeeding lead to lower blood cholesterol in adult life? A quantitative review of the evidence. Am J Clin Nutr 88: 305-314.

Paradkar M, Irudayaraj J (2002) Determination of cholesterol in dairy products using infrared techniques: FTIR spectroscopy. Int Diary Technol 55: 127-132.

Reiser R, Sidelman Z (1972) Control of serum cholesterol homeostasis by cholesterol in the milk of the suckling rat. J Nutr 102: 1009-1016.

Scopesi F, Zunin P, Mazzella M, Testa M, Boggia R, Eevangelisti F, Serra G (2002) 7-ketocholesterol in human and adapted milk formulas. Clin Nutr 21: 379-384.

Syahariza ZA, Che Man YB, Selamat J (2005) Detection of lard adulteration in cake formulation by FTIR spectroscopy, Analytical, Nutritional and Clinical Methods. Food Chem 92: 365-371.

Talpur FN, Bhanger MI, Khuhawar MY (2006) Comparison of fatty acids and cholesterol content in the milk of Pakistani cow breeds. J Food Comp Anal 19: 698-703. 